Original Research Paper

\title{
Intelligent Attendance System Using Artificial Neural Network Based on Students' Background
}

\author{
${ }^{1}$ Daban Abdulsalam Abdullah, ${ }^{1,2,3}$ Karzan Wakil and ${ }^{1}$ Shwan H.H. Alshatri \\ ${ }^{1}$ Research Center, Sulaimani Polytechnic University, Sulaimani 46001, Kurdistan Region, Iraq \\ ${ }^{2}$ Department of Computer, College of Science, University of Halabja, Halabja 46018, Kurdistan Region, Iraq \\ ${ }^{3}$ Department of Information Technology, National Institute of Technology, Sulaimani 46001, Kurdistan Region, Iraq
}

\author{
Article history \\ Received: 23-03-2020 \\ Revised: 03-06-2020 \\ Accepted: 20-07-2020 \\ Corresponding Author: \\ Karzan Wakil \\ Research Center, Sulaimani \\ Polytechnic University, \\ Sulaimani 46001, Kurdistan \\ Region, Iraq \\ Email: karzanwakil@gmail.com
}

\begin{abstract}
Determining the rate of student attendance is an important task in determining the completion of the courses. Despite the success of the technology, it is unfortunate that in many academic institutions, the current systems used to detect student absences. Furthermore, one of the crucial problems in the attendance system does not count student background for continuing in the courses. In this study, we propose an intelligent approach for calculating student attendance based on their Grade Point Average (GPA) and their activities, this approach uses Artificial Neural Network (ANN) for proposing an intelligent attendance system to calculate the attendance rating accurately, meaning the system provide a new rating for each student based on their background. The aim of this research is developing an attendance system for motivation students taking attendance or taking high grade in the class. The result of this approach helps the instructor to allow students who have more activities with more absents to continue in the courses, if not the students have low activity should taking high attendance. This system will more efficient for monitoring students in the classes and replacing absent to activity.
\end{abstract}

Keywords: Attendance System, ANN, Student GPA, Intelligent Education System

\section{Introduction}

Education and science in countries are the keys to the success of nations. Therefore, many of the leading science institutes are trying to gather complete information about the daily behavior of students at the university, internal and external research center assessment, daily activates. All of the teaching methods mentioned a set of data that related to the progress of students in the field of academics, student activity groups such as seminars, daily activities in the classroom, student attendance and absence are important data so that can assess students' abilities (Kumar and Salal, 2019).

The development of information and technology in the field of education has led to better management of information. Many design techniques are the best way to get information so that we can anticipate changes and analyzes. For example, in many Thai universities developed an advanced system for students who want to master a subject, in this case they can achieve a good grade in the end. In other words, they are trying to figure out what kind of topic is appropriate for the student. The Neural Network (NN) technique is a great way to help students to complete their assignments with excellent grades. In other words, the NN does the work for them (Jusoff et al., 2009).

Moreover, due to the availability of job opportunities, parents more likely motivated by their choice of courses and pressures on their children. The problem may arise the student is not interested in the subject, or if a student could not understand this course in a good way and this will make it easier for the student to be more absent to course and there is less participation in their lessons (Ahmed et al., 2008).

The system of student attendance is very important in determining the amount of student participation in their lectures. One of the most important situations is the student's readiness for the faculty member to be able to determine the student's activities and universities use the necessary metrics to reduce student absenteeism. For instance, using the bar-codes to take a decision the arrival of students to bring down excessive absenteeism (Al Sheikh et al., 2019). 
Furthermore, there are several technologies have been developed by researchers. As well as their absences caused problems when they came into their classes to take more time and their numbers were due to the lack of any tools and had to be entered classically by hand (Sawhney et al., 2019).

In addition, operating systems such as Android and Apple sometimes collaborate on the advancement of technologies. They have also been very influential in terms of serving students, especially in determining the number of absences and creating Quick Response (QR) codes that have been placed on mobile systems. The only thing that mattered was the students when they entered the classrooms, the only capture his/her face then they showed were the QR codes by using his/her smartphone. (Sunaryono et al., 2019). Moreover, another study in (Pathan, 2019) proposed an attendance system by using facial recognition with Artificial Intelligence (AI).

Both intrinsic and extrinsic motivations may explain why students come to class. Some factors can affect students' performance and knowledge, the most important of these factors is the amount of participation or absent in the study class and the course will be difficult with the ability of the student (Chou and Kuo, 2012).

However, a lot of study proposed for managing attendance systems by using different techniques, but a big gap in this system is student background for continuing in the courses such as student Grade Point Average (GPA) from previous semesters or current marks in same course or any factor that shows student can pass when less attendance in the class. In this study, we solve this issue by using Artificial Neural Network (ANN) for current systems. The contribution of this work is how students less participate in class and pass in the course with remain the quality of learning.

This paper organized as follows: Section 2 explains the background work on attendance system with different techniques as well as improving using artificial Intelligence. The section 3 prepared research process for proposing attendance system using ANN. In the section 4 , we presents the result of the new attendance system and section 5 presents some concluding remarks and points to future works.

\section{Literature Review}

Various studies have established that there is a correlation between students' attendance and their academic performance and identified that attendance has an encouraging effect on the GPA of students in exams. It was also found that as compare to the students who were not attending all lectures, the students who attended the lectures scored 9.4 to $18 \%$ better in their exams relationship between students' performance and class attendance in a programming language subject in a computer course (Chen and Lin, 2008). In this section, we reviews the most important works on attendances system and their effect on maximum learning.

Widely believed that attendance has a positive effect on student performance in terms of grades achieved. While the empirical evidence generally supports this belief, some studies do not and the size of the effect varies across disciplines. Interestingly, (Durden and Ellis, 1995) find that attendance only has a positive/negative and significant impact on student performance below/above a certain threshold using intercept shift dummies (Durden and Ellis, 1995). Gendron and Pieper (2005) as well as (Westerman et al., 2011) have confirmed a similar non-linear relationship using a quadratic function of attendance and logistic regressions based on 3 different quartiles of performance, respectively (Gendron and Pieper, 2005; O'Dwyer, 2011; Stewart, 2020).

Lukas et al. (2016) proposed a method for a student attendance system in the classroom using face recognition technique by combining Discrete Wavelet Transforms (DWT) and Discrete Cosine Transform (DCT) to extract the features of student's face that are followed by applying Radial Basis Function (RBF) for classifying the facial objects. From the experiments which are conducted by involving 16 students situated in the classroom setting, it results in 121 out of 148 successful faces recognition (Lukas et al., 2016).

Likewise, new systems such as android technology are important for ensuring student absenteeism. In this point some suggestions on how to look or get an appointment for student attendance, the teacher of the lesson can easily get the number of students by using the mobile application they designed, storing the data and then sending it to the server can then extract the percentage of students and also can be used as the hard copy. In like manner, the stored information is used attendance percentage calculations (Islam et al., 2017).

A large number of studies performed using the bimodal biometrics system, biometrics to improve the number to better identify automatic student attendance system, then the system uses the face and fingerprint to take students' attendance. In the same way, fingerprint templates and facial images can be combined by used logical technique (OR) used to store in the database (Charity et al., 2017).

Nevertheless, (Tung, 2017) proposed a new student attendance system using Radio Frequency Identification Device (RFID) in the Tunku Abdul Rahman University College. This system has a very low cost and is very accurate in recognizing the readiness of the lessons (Tung, 2017).

The usual way to do this is in most scientific institutions, meaning that some of them use the name or signature of the student to know the number of 
participants. To make the data more accurate, there are many ways to test it, especially face recognition technology, which is a technique that is used to expose the number of students in absent and to reduce the waste of time (Bhattacharya et al., 2018).

An automated system was de facto for many systems; Khan et al. (2017) the aim of this project is to eliminate the paper-based attendance changed to auto attendance by using a student ID card. In the same way, card based attendance and students in universities and employees in companies use webbased attendance. If the paper-based attendance was lost or missing, many employers try to $\log$ in the system at the same time but the system gets down. The solution to this problem is to find a way to use Wi-Fi-based attendance (Khan et al., 2017).

With continuing auto attendance system (Shaik and Islam, 2019) common methods have been used to ensure their readiness and then they are going to use an automated attendance system to detect common methods it is called Corny approach. An automated attendance system used to prevent students from trying to trick into entering their classrooms. The method used was composed of using face detection and recognition. Likewise, Face detection is used to different facial expressions from others and recognition method recognizes the person for daily attendance (Shaik and Islam, 2019).

Attendance monitoring system is basic to determining activities is an easy way to know if students are ready or not. This is a difficult task, but the least amount of errors can made. We do not have much time to spare and we do not need to read the student's signature or name every time in the classroom. Face detection and recognition framework used to compare the data that obtained with the data that is stored in the database, to match and marking attendance (Kumar et al., 2018).

An interesting work by (Ahmed et al., 2020) on the relationship between student activities throughout the study period and students' class attendance. Students' activates are assessed via query's assignments, midterm exam, homework's. Preliminary analyzes indicated that students an increase of $10 \%$ class attendance, In the same way, it increases the number of students' activities by 8 to $15 \%$ in the same way that they are more available in the classroom that there is a very strong functional relationship between class attendance and students' academic performance, so it was decided. It has a positive effect on the academic workforce and therefore a policy of compulsory attendance has been proposed to be established in all branches of the College of Science at Thomson Rivers University (Ahmed et al., 2020).
In latest works at 2019 and 2020, AI techniques have been used in many areas of daily human life, so it has a very high impact on our daily lives as well as machine learning, deep learning, ANN and big data. A combination of the Histogram of Oriented Gradients (HOG) and NNs are used to determine the number of students in the study halls, as well as all other studies, to measure the benefit automated system (Rajeev et al., 2019).

In the recent works for providing reliable and time saving Internet Of Things (IOT) used to automatic attendance system as shown in (Salman et al., 2019). In another work (Chen and $\mathrm{Li}, 2020$ ) used IOT for designing intelligent campus and smart system including attendance management system, also IOT with using biometric used to intelligent attendance system (Dmello et al., 2019; Mon et al., 2019; Srivastava et al., 2019; Al_Janabi, 2020; Vatwani et al., 2020). Finally, a number of systems proposed to control attendance system but still need to improve the system.

\section{Research Methodology}

In this section, we define a methodology for intelligence attendance system; this methodology consists of several steps. In the first step, we define the attendance system in the university. The second step prepares an ANN for our system; the third step implementing the NN in the system, the fourth step is evaluation effect of ANN on the result as shown in Fig. 1.

First step: Classic Attendance System allows students absent in class by rating $15 \%$, if the student's absence more than $15 \%$ will fail in the course.

Second Step: In this step, we use ANN for intelligence attendee system with the following formula in the hidden layer. We use the criteria for changing the rate of absence. The craters are previous GPA, current GPA and Activity.

Third Step: We implement ANN technique to classic attendance system.

Fourth Step: We will compare classic attendance system and intelligence attendance system then we evaluate the effectiveness of the result.

The recurrent NN implemented through a supervised learning algorithm. In this system the input data of absents that are GPA, Marks and activities are taken continuously from the user and is stored in the memory. After than all sequences of data is fed to this network that becomes the learning data for the system. Then the machine through proposed formula calculate the new rate for attendance of students, the system is able to track changes in human behavior with time. In the next section, this methodology will implement to find the result of the approach through ANN. 


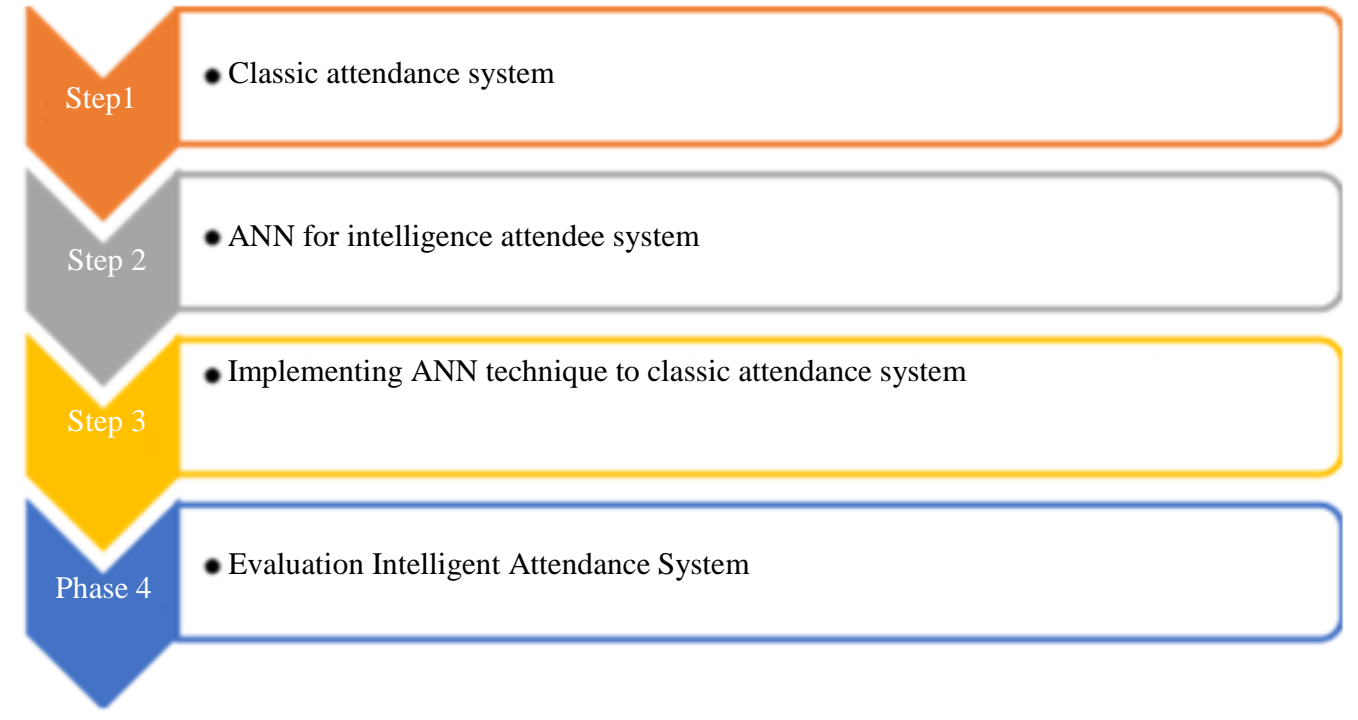

Fig.1: Research process for intelligent attendance system

\section{Results and Discussion}

The standard rate is a set of absence is $15 \%$ for each courses when can't be more than that. If a student absence higher than this rate, the student will counted fail according to some university standards and if we get higher than that, we will highlight a few of the students' positive points such as daily activities in the classroom, GPA from previous semesters and current marks in this semester.

To reduce the number of attendance students so that they can continue to study without falling into disrepair. This means that we will increase the absenteeism rate of this student, which means that if this student has a high GPA or a lot of activity, he/she will be able to ignore absenteeism rate this student more. However, we have used the equation to be able to increase the student absenteeism rate to a certain extent, which means that we ignore the student absenteeism until we have a certain amount of self-determination. In other words, only those students can be targeted and the rate of absenteeism is between 5 to $25 \%$. In general, here is an eliminated of students who have been able to succeed at GPA, Marks and Activities, which means that they have grade above $50 \%$.

\section{Classic Attendance System}

The usually absent rate for each course consists of $15 \%$, meaning each student can absence in each class $15 \%$ as shown in Table 1 .

This rate for some students not enough especially smart students or students who can pass with less attendance in the class. Also too much for students who have fewer marks or cannot pass easily in the course. For example, if we have some students with different courses, the rate for each course is $15 \%$. The classic attendance system with absent rate presents in Table 1. In addition, this absent rate presented by MATLAB codes in Fig. 2 and the graph of the codes presented in Fig. 3 that shows the strait line and $15 \%$ for each student.

\section{ANN for Attendance System}

ANN or connectionist systems are computing systems vaguely inspired by the biological NNs that constitute animal brains. Such systems "learn" to perform tasks by considering examples, generally without being programmed with task-specific rules. In this section, we propose a new model for attendance system based on ANN as shown in Fig. 4. In the input layer, several criteria entered absent rate, student GPA from the previous semester, Current marks and student activities. In the hidden layer, a mathematical formula uses for finding suitable absent rate for each student in any courses as shown in Equation 1. The output layer will be the intelligent absent rate for each student for the courses. As shown in Fig. 4:

$$
I A R=\operatorname{Min}(A)+\left[\left(\sum_{i=1}^{n} \frac{x_{i}}{n}-\operatorname{Min}(M)\right) \times \frac{\operatorname{Max}(M A)}{\operatorname{Min}(M)}\right]
$$

IAR: $\quad$ Intelligent absent rate

$\operatorname{Min}(A)$ : Minimum absent that allows for each student is $5 \%$

$\operatorname{Min}(M): \quad$ Minimum mark for pass is $50 \%$

$\operatorname{Max}(M A)$ : maximum absent rate when student can add through activities $20 \%$

$X i$ The criteria like GPA, Marks and activities 


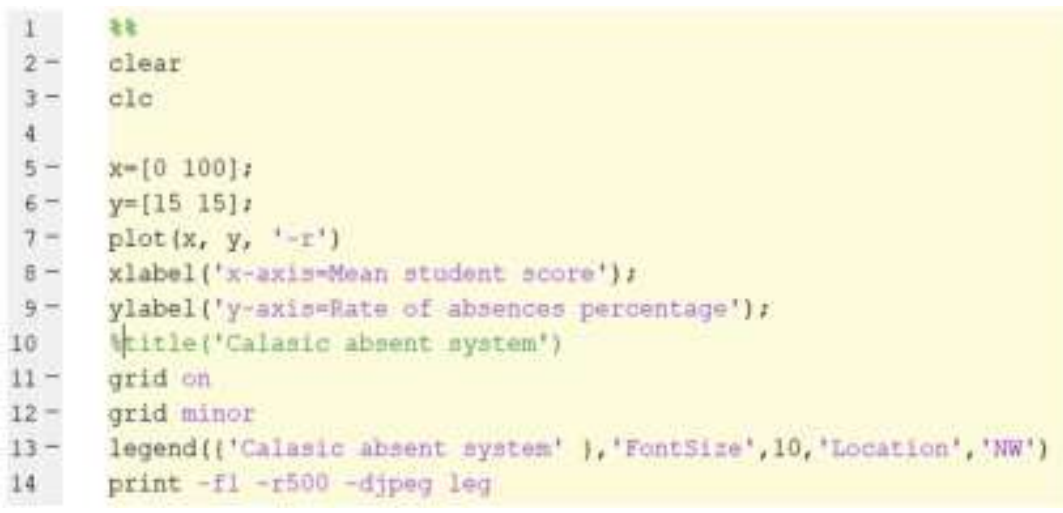

Fig. 2: MATLAB codes for classic attendance system

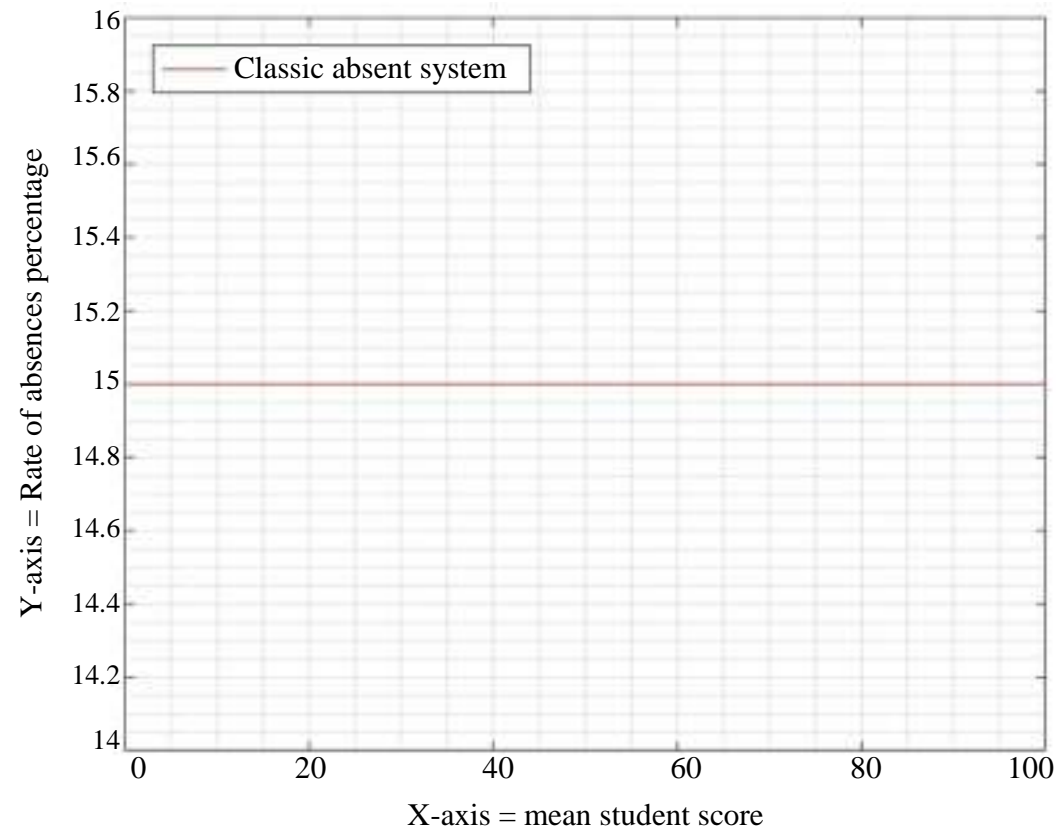

Fig. 3: Classic attendance system per course

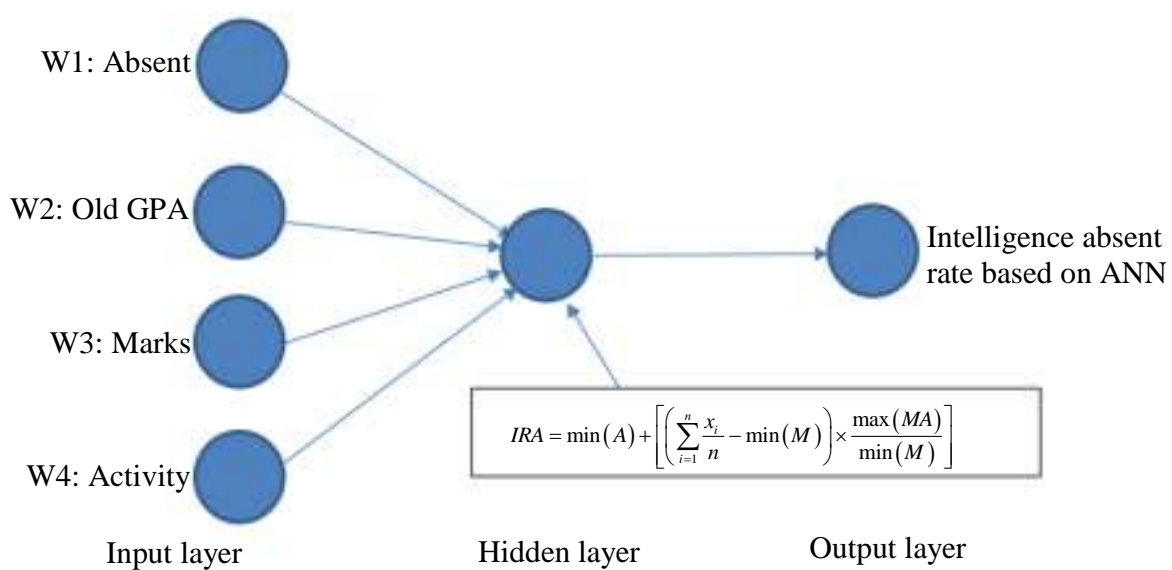

Fig. 4: ANN for intelligent attendance system 
Table 1: Classic attendance system

\begin{tabular}{llll}
\hline No. & Student name & Courses code & Absent rate \\
\hline 1 & Student1 & AI232 & $15 \%$ \\
2 & Student2 & AI232 & $15 \%$ \\
3 & Student2 & SE235 & $15 \%$ \\
4 & Student3 & AI232 & $15 \%$ \\
5 & Student3 & SE235 & $15 \%$ \\
6 & Student4 & AI232 & $15 \%$ \\
7 & Student4 & SE235 & $15 \%$ \\
8 & Student4 & OS261 & $15 \%$ \\
9 & Student5 & AI232 & $15 \%$ \\
10 & Student5 & SE235 & $15 \%$ \\
\hline
\end{tabular}

Table 2: Intelligent attendance system

\begin{tabular}{|c|c|c|c|c|c|c|}
\hline No. & Student name & Courses code & GPA & Marks & Activities & Absent rate \\
\hline$\overline{1}$ & Student1 & AI232 & $99 \%$ & $99 \%$ & $99 \%$ & 24.60 \\
\hline 2 & Student2 & AI232 & $75 \%$ & $75 \%$ & $75 \%$ & 15.00 \\
\hline 3 & Student2 & SE235 & $50 \%$ & $50 \%$ & $50 \%$ & 5.00 \\
\hline 4 & Student 3 & AI232 & $100 \%$ & $100 \%$ & $100 \%$ & 25.00 \\
\hline 5 & Student3 & SE235 & $50 \%$ & $50 \%$ & $50 \%$ & 5.00 \\
\hline 6 & Student4 & AI232 & $50 \%$ & $60 \%$ & $50 \%$ & 6.33 \\
\hline 7 & Student4 & SE235 & $70 \%$ & $60 \%$ & $50 \%$ & 9.00 \\
\hline 8 & Student4 & OS261 & $100 \%$ & $80 \%$ & $50 \%$ & 15.66 \\
\hline 9 & Student5 & AI232 & $90 \%$ & $50 \%$ & $50 \%$ & 10.30 \\
\hline 10 & Student5 & SE235 & $80 \%$ & $50 \%$ & $70 \%$ & 11.66 \\
\hline
\end{tabular}

According to the above equation known as the Fig. 4, we have used three criteria to give us a real result that is close to reality. These three inputs are (Old GPA, Marks and Activity) is taken as an example and we can add them to how many other inputs. For example if we add another criteria, the formula automatically counted as fourth criteria $\left(X_{4}\right)$ and divided by $(n)$ will be (4), in this case we will get real result, we can say that we have found this equation to be very flexible to increase any inputs.

The algorithm of Fig. 4 for finding suitable absent rate presented in Fig. 5.

For example, one of our students has a higher attendance rate than the standard, $15 \%$ that we mentioned. That is, the percentage of attendance to be present is $16 \%$. This means that these students will be failing according to university standards, but will based on current GPA, new GPA, Activity-class and the equations we are referring to, there seems to be more opportunity to continue in the course. As shown in Table 2.

To clarify these actions, we will discuss and analyze some of these examples in this study to understand more. About the use of this new equation that we have identified to find out more about how we can solve student absentee statistics, we recommend that he/she continue to study in that course if you have exceeded the amount of the Central Teaching Act.
Let us look at the first-row sample to find out the analysis of the equations that we have defined. How many collaborators are there to come up with the right results?

Here is an example of a student taking a course with an (A1232) course code that has a high GPA (99), Mark (99) and daily activities (99). Likewise, we will use these grades in Equation (1) to determine how long this student will allowed to absent in this course.

$$
\begin{gathered}
I A R=5+\left[\left(\left(\frac{99+99+99}{3}\right)-50\right) * \frac{20}{50}\right] \\
I A R=\frac{123}{5} \approx 24.6
\end{gathered}
$$

For first raw: Student No.1 course code (A1232), If we pay attention here, the second Student No.2 in the (A1232) course code will have a Mark, GPA and Activities grade in the middle grade. Therefore, he or she can be absent to the extent specified we mentioned in the Central Teaching Act standard (15) h.

For second raw: Student No.2 course (SE235):

$$
\begin{aligned}
& I A R=5+\left[\left(\left(\frac{75+75+75}{3}\right)-50\right) * \frac{20}{50}\right] \\
& I A R=0+5=15
\end{aligned}
$$

If we pay attention here, the second Student No. 2 in the (A1232) course code will have a Mark, GPA and Activities grade in the middle grade. Therefore, he or she can be absent to the extent specified we mentioned in the Central Teaching Act standard (15) h: 


$$
\begin{aligned}
& I A R=5+\left[\left(\left(\frac{50+50+50}{3}\right)-50\right) * \frac{20}{50}\right] \\
& I A R=0+5=15
\end{aligned}
$$

For third raw: Student No.2 course (SE235), Here we have the same Student No.2 but a different course (SE235). On the other hand, this student has a low GPA, Mark and Activities scores so he can be absent for (5) hours. Finally, we can say the same for all courses and students in the same way.

\section{Implementation}

In this section, we present the implementation of the new ANN for attendance system using MATLAB software. In the Fig. 6 the result of our model illustrated, based on the graph with increasing mean of activities that are (GPA, Marks and Activities) the rate of absent increased, the minimum activities is $50 \%$ the absent rate is $5 \%$,

When the mean of activities increased the rate of absent will be increased, when the maximum amount of absent rate is $25 \%$ when the mean of activities like (GPA, Marks and Activities) become too $100 \%$.

Also, this absent rate presented by MATLAB graph in Fig. 4, this figure shows that strait line and the students who failed to succeed were pointed out by the red line. In common, this means that all their scores in GPA, Marks and Activities are below 50. However, the students who were able to achieve the success rate were determined by the average grade, which means that it starts from 50 until 75 we mentioned by the blue line. As well as the amount of absenteeism is determined from 5 to $15 \mathrm{~h}$. The red line, which starts at the top of the 75 score, allows these students to be absent for up to $25 \mathrm{~h}$, meaning that students have a high level of knowledge.

The Matlab Code for Fig. 6 presented in Fig. 7.

$$
\begin{aligned}
& \text { Int } A=5 \% ; \\
& \text { Float } T=50 \% ; \\
& \text { Float } P=20 \% ; \\
& \text { Float } X ; \\
& \text { Int } n ; \\
& \text { Input } n ; \\
& \text { For } i=1 \text { to } n \\
& \{ \\
& \text { Input } X ; \\
& X=X+X[i] ; \\
& \} \\
& \text { IRA }=A+\left((X-T)^{*} P / T\right) ;
\end{aligned}
$$

Print IRA. "\%",

Fig. 5: Algorithm of intelligent attendance system

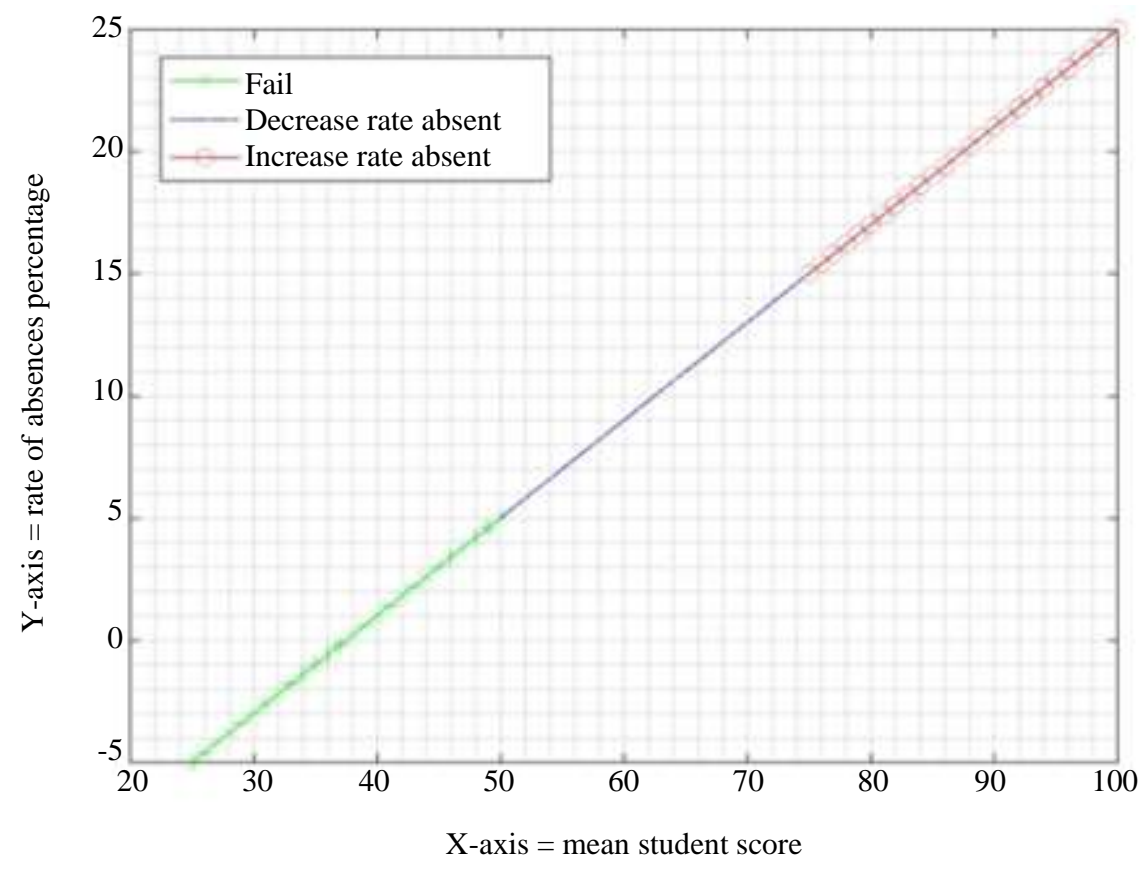

Fig. 6: Intelligent attendance system per course 


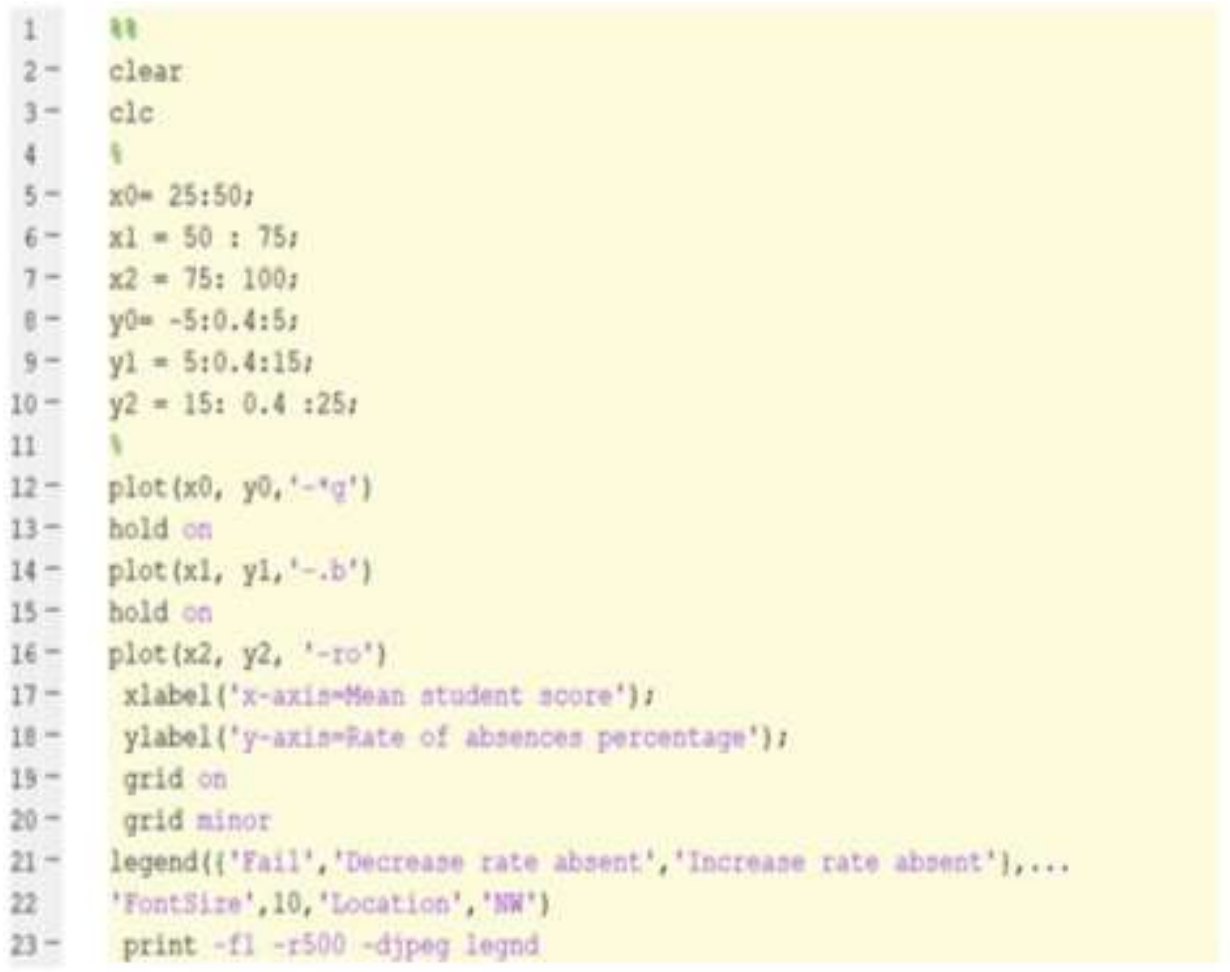

Fig. 7: MATLAB codes of intelligent attendance system per course

\section{Evaluation Intelligent Attendance System}

The intelligent absent system more efficient compare with classic attendance system, this system consists of three cases. The first case gives $5 \%$ of rate absent even student ignore activities and get lowest marks, this rate increased with increasing mean of activities, in this case, students that have low activities must be taken more attendance and provide more learning for students. The second case when the mean of activities $75 \%$ of students takes $15 \%$ like the classical system, this case allows the student to get the normal absent rate. In the third case, student can take an extra $10 \%$ when activities become to $100 \%$, this case allows smart students to take low attendance with high marks. Finally, we can say this system very smart and increase the efficiency of learning.

\section{Conclusion and Future Work}

In this study, we proposed an intelligent approach for calculating student attendance based on their Grade Point Average (GPA) and their activities, this approach uses ANN for providing attendance intelligent system to calculate the attendance rating accurately. The result of our approach more efficient compared with previous systems that counted manually or only used one criteria to calculate attendance system. Our novel approach use more than one criteria and background student to find a new rate or intelligent rate for absence each student. In this approach student can get extra or lost $10 \%$ of absent arte based on activity and background of his GPA. We recommend to researcher improve this system through different techniques like data mining Conventional Neural Network (CNN), moreover mixed with fingerprint and any image processing techniques to present accurate and high result.

\section{Acknowledgement}

We would like to thanks for Research Center in Sulaimani Polytechnic university for financial supporting, as well as thanks for National Institute of Technology in the process collecting and extracting data as real case study.

\section{Author's Contributions}

Daban Abdulsalam Abdullah: Defining idea data collection, writing the papers and developing the references.

Karzan Wakil: Improving idea and supervision.

Shwan H.H. Alshatri: Mathematical equations test the results.

\section{Ethics}

It is testified by the authors that this article has not been published anywhere else and contains no ethical issues. 


\section{References}

Ahmed, E., Tomal, J., \& Rahman, M. (2020). 1-The Impact of class attendance on student performance at TRU.

Ahmed, N., Gamage, D. T., Suwanabroma, J., Ueyama, T., Hada, S., \& Sekikawa, E. (2008). The impact of quality assurance measures on student services at the Japanese and Thai private universities. Quality assurance in Education.

Al Sheikh, R., Al-Assami, R., Al-Bahar, M., Al Suhaibani, M., Alsmadi, M., Alshabanah, M., ... \& Tayfour, M. (2019). Developing And Implementing A Barcode Based Student Attendance System. International Research Journal of Engineering and Technology (IRJET) Volume, 6.

Al_Janabi, S. (2020). Smart system to create an optimal higher education environment using IDA and IOTs. International Journal of Computers and Applications, 42(3), 244-259.

Bhattacharya, S., Nainala, G. S., Das, P., \& Routray, A. (2018, July). Smart attendance monitoring system (SAMS): a face recognition based attendance system for classroom environment. In 2018 IEEE 18th International Conference on Advanced Learning Technologies (ICALT) (pp. 358-360). IEEE.

Charity, A., Okokpujie, K., \& Etinosa, N. O. (2017, November). A bimodal biometrie student attendance system. In 2017 IEEE 3rd International Conference on Electro-Technology for National Development (NIGERCON) (pp. 464-471). IEEE.

Chen, J., \& Lin, T. F. (2008). Class attendance and exam performance: A randomized experiment. The Journal of Economic Education, 39(3), 213-227.

Chen, W. J., \& LI, H. F. (2020). Study on the Intelligent Campus System of the Internet of Things. DEStech Transactions on Social Science, Education and Human Science, (icesd).

Chou, P. T., \& Kuo, Y. (2012). Examining factors relating to classroom attendance and performance. Journal of Studies in Education, 2(2), 193-204.

Dmello, R., Yerremreddy, S., Basu, S., Bhitle, T., Kokate, Y., \& Gharpure, P. (2019, January). Automated Facial Recognition Attendance System Leveraging IoT Cameras. In 2019 9th International Conference on Cloud Computing, Data Science \& Engineering (Confluence) (pp. 556-561). IEEE.

Durden, G. C., \& Ellis, L. V. (1995). The effects of attendance on student learning in principles of economics. The American Economic Review, 85(2), 343-346.

Gendron, P., \& Pieper, P. (2005). Does attendance matter? Evidence from an Ontario ITAL. Unpublished discussion paper, Humber Institute of Technology \& Advanced Learning Toronto, Canada, 15.
Islam, M. M., Hasan, M. K., Billah, M. M., \& Uddin, M. M. (2017, December). Development of smartphonebased student attendance system. In 2017 IEEE Region 10 Humanitarian Technology Conference (R10-HTC) (pp. 230-233). IEEE.

Jusoff, K., Samah, S. A. A., \& Isa, P. M. (2009). Promoting University Community's Creative Citizenry. International Journal of Human and Social Sciences, 4(1), 25-30.

Khan, M. B., Prashanth, N. M., Nomula, N., Pathak, P., \& Muralidhar, A. M. (2017). Auto Student Attendance System Using Student ID Card via Wi-Fi.

Kumar, M., \& Salal, Y. K. (2019). Systematic Review of Predicting Student's Performance in Academics. Int. J. of Engineering and Advanced Technology, 8(3), 54-61.

Kumar, V. A., Kumar, V. A., Malathi, S., Vengatesan, K., \& Ramakrishnan, M. (2018). Facial recognition system for suspect identification using a surveillance camera. Pattern Recognition and Image Analysis, 28(3), 410-420.

Lukas, S., Mitra, A. R., Desanti, R. I., \& Krisnadi, D. (2016, October). Student attendance system in classroom using face recognition technique. In 2016 International Conference on Information and Communication Technology Convergence (ICTC) (pp. 1032-1035). IEEE.

Mon, S. S., Kham, N. S. M., \& Aung, T. H. (2019, February). Application of RFID based Student Attendance System using Cloud Storage and IOT. Seventeenth International Conference on Computer Applications (ICCA 2019).

O'Dwyer, A. (2011). Does a link exist between examination performance and lecture attendance for first year engineering students?.

Pathan, S. (2019). Student attendance system using facial recognition with AI.

Rajeev, A., Rebbi, J., Correya, J. G., Prabhu, V. V., \& James, D. (2019). HOG-Neural Network Based Student Attendance System.

Salman, H., Uddin, M. N., Acheampong, S., \& Xu, H. (2019, March). Design and Implementation of IoT Based Class Attendance Monitoring System Using Computer Vision and Embedded Linux Platform. In Workshops of the International Conference on Advanced Information Networking and Applications (pp. 25-34). Springer, Cham.

Sawhney, S., Kacker, K., Jain, S., Singh, S. N., \& Garg, R. (2019, January). Real-Time Smart Attendance System using Face Recognition Techniques. In 2019 9th International Conference on Cloud Computing, Data Science \& Engineering (Confluence) (pp. 522525). IEEE. 
Shaik, M., \& Islam, A. (2019). Automated Attendance System Using Face Recognition with One-Shot Learning and Siamese Neural Networks.

Srivastava, P., Tripathi, S., \& Kumar, M. (2019). Design and Implementation of an Intelligent Biometric Attendance System using IoT.

Stewart, C. (2020). An exploratory threshold regression model of the relationship between student performance and attendance (No. 2020-1).

Sunaryono, D., Siswantoro, J., \& Anggoro, R. (2019). An android based course attendance system using face recognition. Journal of King Saud UniversityComputer and Information Sciences.
Tung, W. S. (2017). Student Attendance System Using Radio Frequency Identification Device (RFID) (Doctoral dissertation, Tunku Abdul Rahman University College).

Vatwani, N., Valecha, S., Wadhwani, P., Kataria, V., \& Sengupta, S. (2020). e-Classroom Using IOT to Revolutionize the Classical Way of Knowledge Sharing. In Machine Learning and Information Processing (pp. 27-37). Springer, Singapore.

Westerman, J. W., Perez-Batres, L. A., Coffey, B. S., \& Pouder, R. W. (2011). The relationship between undergraduate attendance and performance revisited: Alignment of student and instructor goals. Decision Sciences Journal of Innovative Education, 9(1), 49-67. 